\section{Case Reports in Neurology}

Case Rep Neurol 2020;12:282-290

DOI: $10.1159 / 000508943$

Published online: September 17, 2020

C 2020 The Author(s)

Published by S. Karger AG, Basel

www.karger.com/crn

This article is licensed under the Creative Commons Attribution-NonCommercial 4.0 International License (CC BY-NC) (http://www.karger.com/Services/OpenAccessLicense). Usage and distribution for commercial purposes requires written permission.

\title{
Volume-Staged Radiosurgery for Large Arteriovenous Malformation
}

\author{
Nguyen Thanh Xuan ${ }^{b} \quad$ Pham Nguyen Tuong $^{a} \quad$ Tran Khoa $^{a}$ \\ Pham Nhu Hiep $^{a} \quad$ Nguyen Van Thanh $^{a}$ Dang Hoai Bao ${ }^{a}$ \\ ancology Center, Hue Central Hospital, Hue City, Vietnam; bepartment of Pediatric and \\ Abdominal Emergency Surgery, Hue Central Hospital, Hue City, Vietnam
}

\section{Keywords}

Arteriovenous malformation · Volume-staged radiosurgery · Digital subtraction angiography

\begin{abstract}
Large arteriovenous malformations (AVMs) are challenges in management because of outcomes and adverse affects. Volume-staged radiosurgery has been an appropriate approach when removal resection and embolization are not recommended. A 53-year-old gentleman was diagnosed with a large intracranial AVM with persistent headache and short-term seizure. Brain magnetic resonance and angiograph showed a bulky volume of AVM nidus. Removal resection and embolization were not recommended because of high risk of adverse affects. The patient was treated by volume-staged radiosurgery. One year post-treatment, obliteration for right internal carotid artery was completed. Volume-staged radiosurgery is a potential treatment option for large AVM with controlled and obliteration efficacy, especially to AVMs which are not appropriate for removal surgery and embolization.

(C) 2020 The Author(s)

Published by S. Karger AG, Basel
\end{abstract}

Nguyen Thanh Xuan and Pham Nguyen Tuong contributed equally to this work.

KARGER

Pham Nguyen Tuong

Oncology Center

Hue Central Hospital

16 Le Loi Street, Hue (Vietnam)

phamnguyentuongubhue@gmail.com 


\section{Case Reports in Neurology}

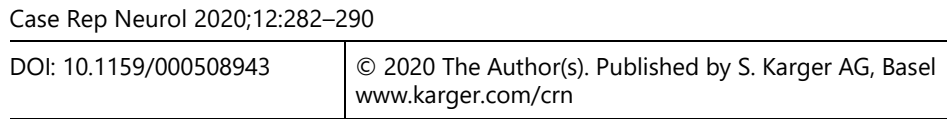

Xuan et al.: Volume-Staged Radiosurgery for Large Arteriovenous Malformation

Arteriovenous malformations (AVMs) are congenital vascular anomalies comprised of an abnormal number of blood vessels that are abnormally constructed. The blood vessels directly shunt blood from arterial input to the venous system without an intervening capillary network to dampen pressure. The annual incidence of AVM recognition is thought to be 10,000 patients per year in the United States [1].

In making a decision for management strategies, we often employ a decision tree algorithm as shown in Figure 1 [2].

Surgical removal is arguably the best option for small- to medium-sized lesions, defined as Spetzler-Martin (Table 1) grades I-III, occurring in noneloquent and superficial regions of the brain, particularly those with a history of hemorrhage [3]. Complete resection is curative and eliminates the risk of hemorrhage without a latent period. Large lesions, usually SpetzlerMartin grades IV and V, have substantially higher surgical complication rates and remain a therapeutic challenge. The overall prevalence or natural history of large AVMs is not well known, but such lesions have also been associated with increased rates of hemorrhage [4]. In most reports, lesion size is defined by the greatest maximal dimension of the AVM nidus, and the incidence of AVMs larger than 2.5-3 cm varies from 30 to $62 \%$ in natural history studies [5].

For larger-volume AVM (average diameter 4-5 cm), observation may be the only reasonable strategy in view of the risks of even multimodality management [6]. This may be especially true for patients who have never bled previously.

Different treatment paradigms for large inoperable AVMs include single-stage stereotactic radiosurgery (SRS), embolization (definitively, pre-SRS, or post-SRS), SRS with planned salvage of surgery or repeat SRS, proton-based SRS, fractionated SRS, dose-staged SRS, and volume-staged (VS)-SRS, which is an alternative approach where the nidus is divided into separate volumes and treated in separate sessions while minimizing overlap between stages [3].

Outcomes after radiosurgery may be predicted based on volume, location, age, angioarchitecture, and dose delivered [7]. SRS is an excellent management strategy for patients with AVMs $30 \mathrm{~mm}$ in average diameter (for a single procedure). Staged procedures are used for larger vascular malformations or for those that were incompletely obliterated 3 years or more after an initial procedure.

VS-SRS has been described as a way to potentially improve rates of obliteration and decrease the normal tissue 12 -Gy volume by $27.3 \%$ and the overall 12 -Gy volume by $11 \%$ compared with a hypothetical single session of SRS [8].

In this study, we introduce a 53-year-old gentleman with large AVM diagnosis, AVM at eloquent site, affected functionally. Removal surgery and endovascular intervention were not available.

\section{Case Report}

A 53-year-old gentleman presented with persistent headache in the past 2 years. He had previously hypertension history, was treated permantly by calcium blocker, without history of vision blur and seizure. He came to the Neurosurgery Department because of increasing headache and short-term seizure. Brain magnetic resonance imaging (MRI) showed a large 


\section{Case Reports in Neurology}

Case Rep Neurol 2020;12:282-290

DOI: $10.1159 / 000508943$
(C)

2020 The Author(s). Published by S. Karger AG, Base www.karger.com/crn

Xuan et al.: Volume-Staged Radiosurgery for Large Arteriovenous Malformation

AVM at right brain lobular, maximum diameter of the AVM nidus was $6.48 \mathrm{~cm}$ (Fig. 2). In digital subtraction angiography (DSA), there were many large and high-flow supplying arteries (the largest was the right internal carotid artery) (Fig. 3). The diagnosis was inoperative large AVM, Spetzler-Martin grade V, inappropriate for embolization. We decided to use VS-SRS with an interval time of 3-6 months. The AVM had been divided into two halves (anterior and posterior) based on the posterior edge of anterior clinoid as landmark. Dose to anterior half was 15 Gy and posterior half was 15 Gy after calculated doses for coverage and organs at risk. Planning target volumes were defined as GTV $+2 \mathrm{~mm}$ (Fig. 4). Simulation was performed by using specific radiosurgery thermomask. Computed tomography simulation and MRI were recorded by $1-\mathrm{mm}$ slice thickness; plans were calculated by dosimetrists and software Monaco 5.1. MRIs and DSA were taken before treatment, between 2 stages, and 3, 6, 12, 18 months after the second stage. Follow-up time was 24 months at the time of report.

First fraction (first stage) was on September 28, 2017, with 15 Gy delivered to the anterior half of the whole AVM. Coverage was $>95 \%$ prescriptive dose to $100 \%$ of volume, maximum dose was 1,847 cGy ( $<140 \%$ prescriptive dose) (Fig. 5).

Forty-eight hours after the first fraction, he felt mild headache, without seizure or dizziness, and the symptom disappeared after $24 \mathrm{~h}$ treated by steroid (dexamethasone $8 \mathrm{mg}$ b.i.d.).

After 4 months, he came for continous treatment. MRI before the second stage showed reduction of whole AVM toward treated half by $20 \%$ (Fig. 6). We decided to make some modifications: alleated borderline between two halves anteriorly (toward treated half) by $2 \mathrm{~mm}$, and decreased dose for second stage at posterior half to $13 \mathrm{~Gy}$, to assure protection to organs at risk (chiasm, right optic nerve).

The second stage was performed on February 26, 2018 (5 months apart).

\section{Discussion}

The Spetzler-Martin AVM grading scale is based on size, location, and venous drainage of intracerebral AVM. The scale is calculated by adding the points for each category. The range is $1-5$. The lower the score, the better the outcome. In our case, other indications such as removal surgery and embolization were not available because of high risk of hemorhage and Spetzler-Martin grade V. Decision on VS-SRS was appropriate. Volume and maximum diameter of AVM nidus were massive, unsafe to adjacent organs at risk if using either single fraction radiosurgery or fractionated routine radiotherapy.

In a subgroup of 48 patients with AVMs larger than $15 \mathrm{~mL}$, Pan et al. [9] found an obliteration rate of $25 \%$ after 40 months. In their single radiosurgery strategy, the average margin dose was 17.7 Gy and 16.5 Gy for AVMs with volumes $10-20 \mathrm{~mL}$ and more than $20 \mathrm{~mL}$, respectively. In their follow-up examinations, they observed $37 \%$ moderate and $12 \%$ severe adverse radiation effects in patients with AVMs larger than $10 \mathrm{~mL}$ [9]. Miyawaki et al. [10] reported that the obliteration rate in patients with AVMs larger than $14 \mathrm{~mL}$ treated using LINAC-based radiosurgery was $22 \%$. Inoue and Ohye [11] reported an obliteration rate of $36.4 \%$ and hemorrhage rate of $35.7 \%$ in the subgroup of AVMs larger than $10 \mathrm{~mL}$ treated by radiosurgery.

The probability of developing post-radiosurgery imaging changes depends on marginal dose and treatment volume. The volume of tissue receiving $12 \mathrm{~Gy}$ or more (the 12 -Gy volume) 


\section{Case Reports in Neurology}

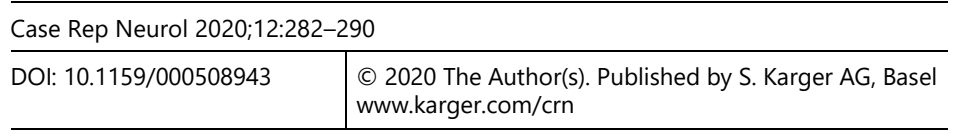

Xuan et al.: Volume-Staged Radiosurgery for Large Arteriovenous Malformation

is the single factor that seems to have the closest correlation with the probability of developing imaging changes [12]. Location does not seem to affect the risk of developing imaging changes but has a marked effect on whether or not these changes are associated with symptoms. Postradiosurgery imaging changes (new areas of high T2 signal in brain surrounding the irradiated AVM nidus) develop in approximately $30 \%$ of patients 1-24 months after radiosurgery [13].

In the present case, post-radiosurgery imaging change was at 4 months after first-stage treatment (whole volume reduced 20\%) without symptoms (Fig. 6). This is appropriate due to dose of 15 Gy at anterior half.

Delayed complications of radiosurgery include the risk of hemorrhage despite angiographically documented completely obliterated AVMs, the risk of temporary or permanent radiation injury to the brain such as persistent edema, radiation necrosis, and cyst formation, and the risk of radiation-induced tumors. Cyst formation after AVM radiosurgery was first reported by Japanese investigators who reviewed the outcomes of patients initially treated in Sweden [14]. Delayed cyst formation has been reported in other recent long-term follow-up studies [15].

Time was a factor contributing to response and obliteration capacity evaluation. Though two stages of treatment had been accomplished, DSA at 6 months still showed remaining shunts (Fig. 7a), while MRI showed complete response. Obliteration evidence presented in DSA only at 12 months after treatment (Fig. 7b, c).

In conclusion, VS-SRS is a potential treatment option for large AVM with controlled and obliteration efficacy. However, indication should be made after very careful discussion by neurosurgeons, endovascular specialists, and radio-oncologists and requires much experience before applying to treatment.

\section{Statement of Ethics}

This study was approved by the Ethical Committee Board of Hue Central Hospital. The authors confirm obtaining written consent from the patient for publication of the manuscript.

\section{Conflict of Interest Statement}

The authors declare no financial disclosures or conflicts of interest.

\section{Funding Sources}

There were no funding sources. 


\section{Case Reports in Neurology}

\section{Author Contributions}

P.N. Tuong and N.T. Xuan carried out and confirmed the diagnosis, provided the details of the case, and contributed to the design of the report. P.N. Tuong and N.T. Xuan drafted the manuscript. All authors read and approved the final version of the manuscript.

\section{References}

1 Deruty R, Pelissou-Guyotat I, Morel C, Bascoulergue Y, Turjman F. Reflections on the management of cerebral arteriovenous malformations. Surg Neurol. 1998 Sep;50(3):245-55.

2 Chapter 10. In: Kalash R, Engh Johnathan A, Amankulor N. Brain Radiosurgery. Stereotactic Radiosurgery and Stereotactic Body Radiation Therapy. SBRT; 2018.

3 Stefani MA, Porter PJ, terBrugge KG, Montanera W, Willinsky RA, Wallace MC. Large and deep brain arteriovenous malformations are associated with risk of future hemorrhage. Stroke. 2002 May;33(5):12204.

4 Flickinger JC, Kondziolka D, Maitz AH, Lunsford LD. Analysis of neurological sequelae from radiosurgery of arteriovenous malformations: how location affects outcome. Int J Radiat Oncol Biol Phys. 1998 Jan;40(2):273-8.

5 Lawton MT; UCSF Brain Arteriovenous Malformation Study Project. Spetzler-Martin Grade III arteriovenous malformations: surgical results and a modification of the grading scale. Neurosurgery. 2003 Apr;52(4):7408.

6 Han PP, Ponce FA, Spetzler RF. Intention-to-treat analysis of Spetzler-Martin grades IV and V arteriovenous malformations: natural history and treatment paradigm. J Neurosurg. 2003 Jan;98(1):3-7.

7 Pollock BE, Flickinger JC. A proposed radiosurgery-based grading system for arteriovenous malformations. J Neurosurg. 2002 Jan;96(1):79-85.

8 Mathis JA, Barr JD, Horton JA, Jungreis CA, Lunsford LD, Kondziolka DS, et al. The efficacy of particulate embolization combined with stereotactic radiosurgery for treatment of large arteriovenous malformations of the brain. AJNR Am J Neuroradiol. 1995 Feb;16(2):299-306.

9 Pan DH, Guo WY, Chung WY, Shiau CY, Chang YC, Wang LW. Gamma knife radiosurgery as a single treatment modality for large cerebral arteriovenous malformations. J Neurosurg. 2000 Dec;93 Suppl 3:113-9.

10 Miyawaki L, Dowd C, Wara W, Goldsmith B, Albright N, Gutin P, et al. Five year results of LINAC radiosurgery for arteriovenous malformations: outcome for large AVMS. Int J Radiat Oncol Biol Phys. 1999 Jul;44(5):1089-106.

11 Inoue HK, Ohye C. Hemorrhage risks and obliteration rates of arteriovenous malformations after gamma knife radiosurgery. J Neurosurg. 2002 Dec;97(5 Suppl):474-6.

12 Friedman WA, Bova FJ, Bollampally S, Bradshaw P. Analysis of factors predictive of success or complications in arteriovenous malformation radiosurgery. Neurosurgery. 2003 Feb;52(2):296-307.

13 Flickinger JC, Kondziolka D, Lunsford LD, Pollock BE, Yamamoto M, Gorman DA, et al. A multi-institutional analysis of complication outcomes after arteriovenous malformation radiosurgery. Int J Radiat Oncol Biol Phys. 1999 Apr;44(1):67-74.

14 Hara M, Nakamura M, Shiokawa Y, Sawa H, Sato E, Koyasu H, et al. Delayed cyst formation after radiosurgery for cerebral arteriovenous malformation: two case reports. Minim Invasive Neurosurg. 1998 Mar;41(1):405.

15 Izawa M, Hayashi M, Chernov M, Nakaya K, Ochiai T, Murata N, et al. Long-term complications after gamma knife surgery for arteriovenous malformations. J Neurosurg. 2005 Jan;102 Suppl:34-7. 


\section{Case Reports in Neurology}

Case Rep Neurol 2020;12:282-290

DOI: $10.1159 / 000508943$

(C)

(c) 2020 The Author(s). Published by S. Karger AG, Basel www.karger.com/crn

Xuan et al.: Volume-Staged Radiosurgery for Large Arteriovenous Malformation

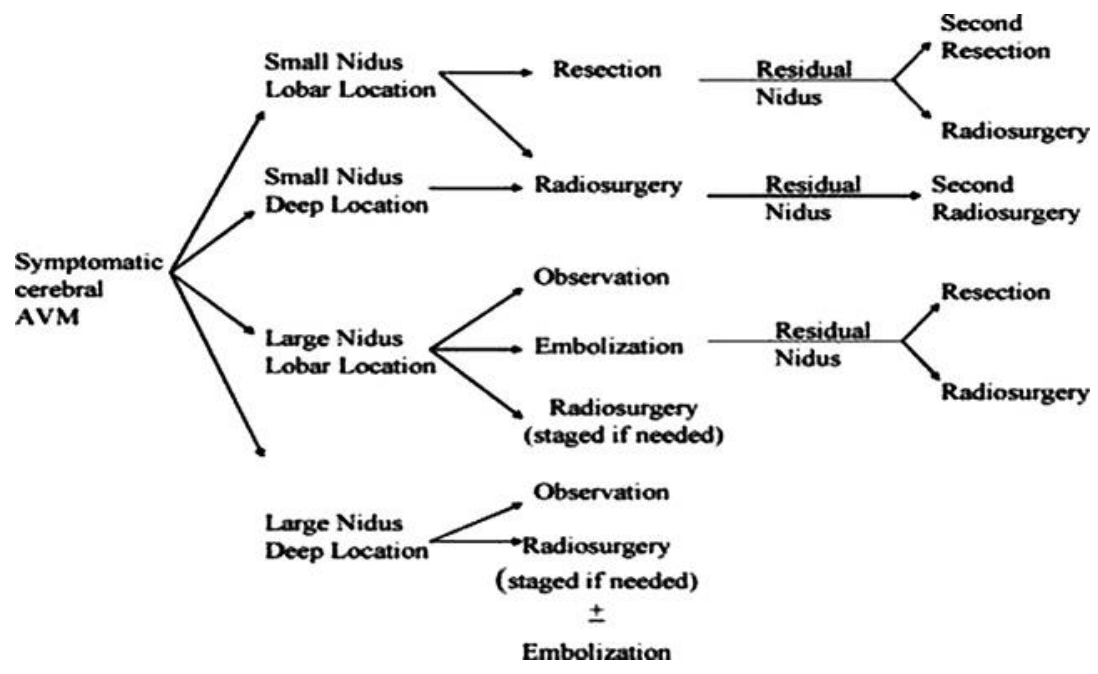

Fig. 1. Treatment strategy for AVM.

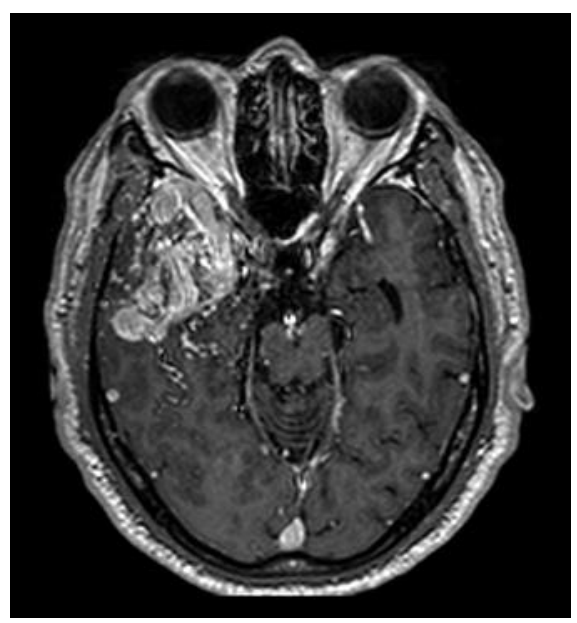

Fig. 2. Pre-treatment MRI. 


\section{Case Reports in Neurology}

Case Rep Neurol 2020;12:282-290

DOI: $10.1159 / 000508943$

(C) 2020 The Author(s). Published by S. Karger AG, Basel www.karger.com/crn

Xuan et al.: Volume-Staged Radiosurgery for Large Arteriovenous Malformation
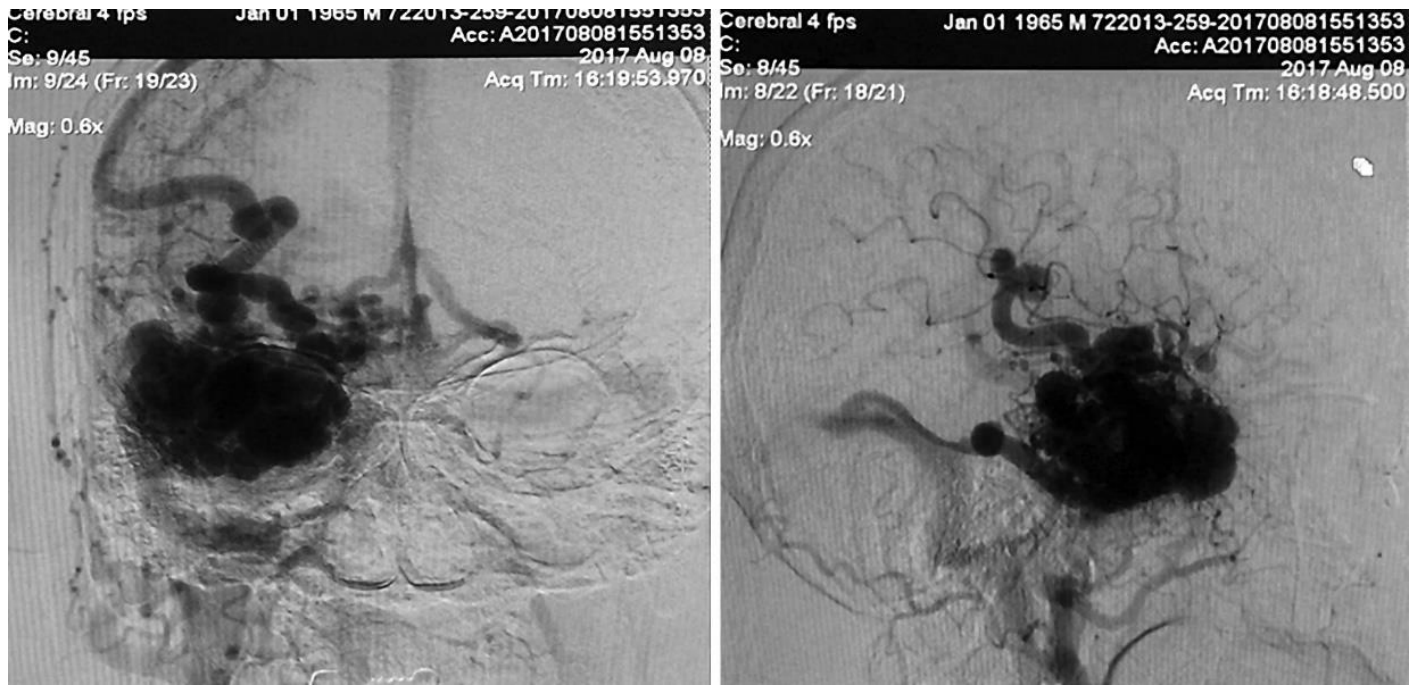

Fig. 3. Pre-treatment DSA.

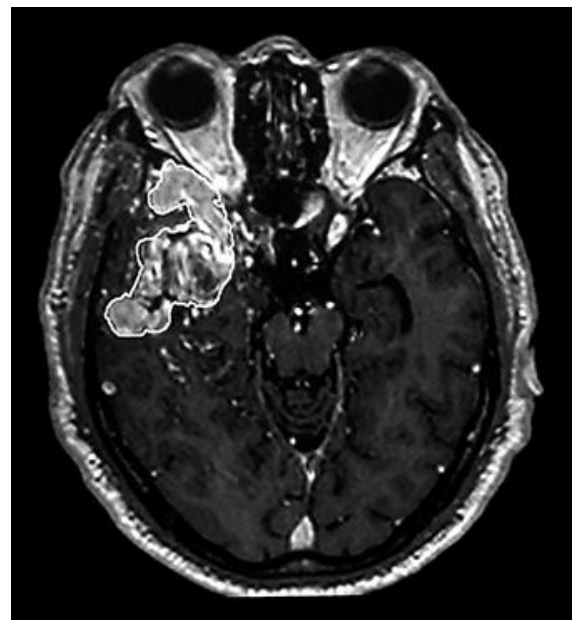

Fig. 4. Whole AVM nidus contouring. 


\section{Case Reports in Neurology}

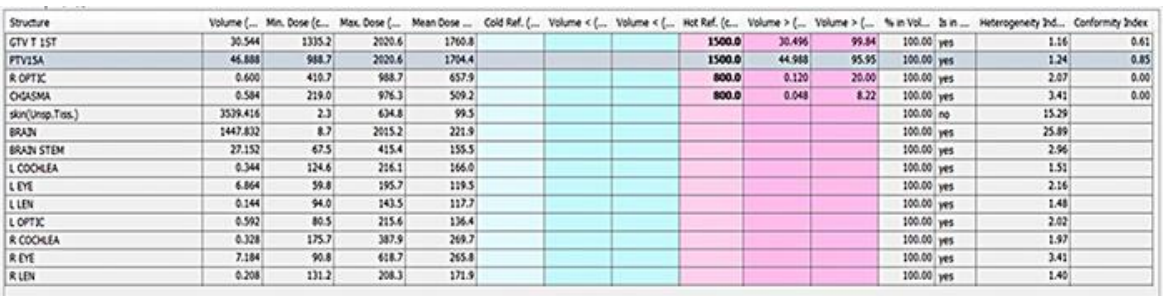

Fig. 5. Dose volume histogram.

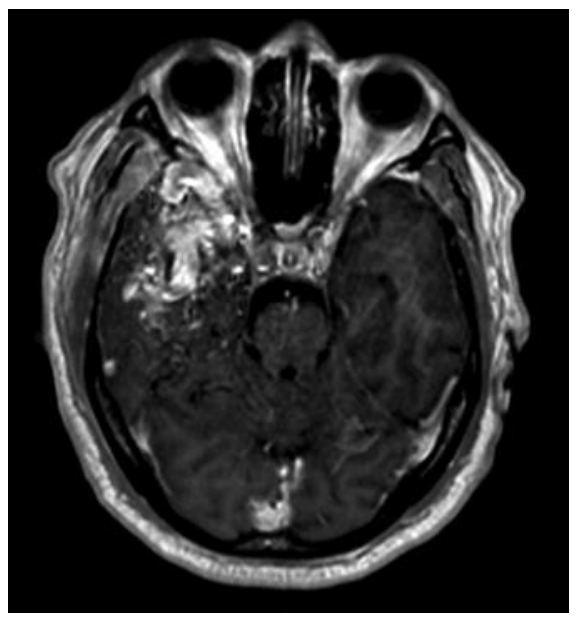

Fig. 6. MRI before second stage.
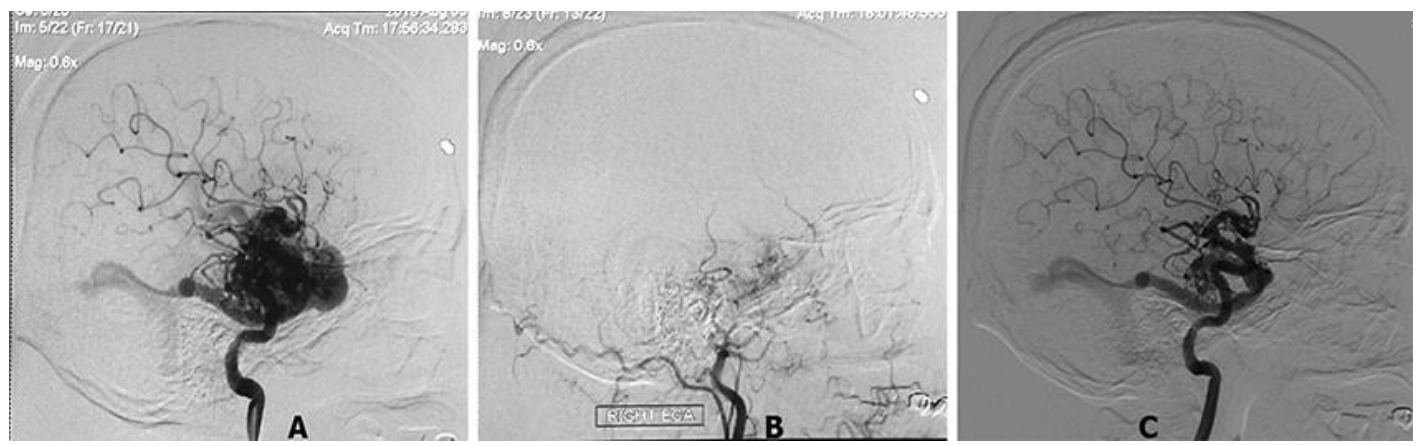

Fig. 7. A Remaining shunts for right internal carotid artery. B Complete obliteration for right external carotid artery. C Complete obliteration for right internal carotid artery. 
Case Reports in Neurology
Case Rep Neurol 2020;12:282-290

DOI: $10.1159 / 000508943$

(c) 2020 The Author(s). Published by S. Karger AG, Basel www.karger.com/crn

Xuan et al.: Volume-Staged Radiosurgery for Large Arteriovenous Malformation

Table 1. Spetzler-Martin AVM grading scale

\begin{tabular}{ll}
\hline & Points \\
\hline Size & \\
$\quad 0-3 \mathrm{~cm}$ & 1 \\
$\quad 3.1-6.0 \mathrm{~cm}$ & 2 \\
$>6 \mathrm{~cm}$ & 3 \\
Location & 0 \\
$\quad$ Noneloquent & 1 \\
$\quad$ Eloquent* & 0 \\
Deep venous drainage & 1 \\
$\quad$ Not present & $1-5$ \\
$\quad$ Present & \\
AVM total score & \\
\hline * Eloquent locations: areas of sensorimotor, language, visual, \\
thalamus, hypothalamus, internal capsule, brain stem. \\
\hline
\end{tabular}

